\title{
Aa. Vv., Langue et sens du "Quart Livre», Actes du Colloque, réunis par Franco Giacone
}

\section{Michele Mastroianni}

\section{Q OpenEdition}

1 Journals

\section{Edizione digitale}

URL: http://journals.openedition.org/studifrancesi/2110

DOI: 10.4000/studifrancesi.2110

ISSN: 2421-5856

\section{Editore}

Rosenberg \& Sellier

\section{Edizione cartacea}

Data di pubblicazione: 1 aprile 2014

Paginazione: 130

ISSN: 0039-2944

\section{Notizia bibliografica digitale}

Michele Mastroianni, «Aa. VV., Langue et sens du «Quart Livre», Actes du Colloque, réunis par Franco

Giacone », Studi Francesi [Online], 172 (LVIII | I) | 2014, online dal 01 avril 2014, consultato il 18 septembre 2020. URL : http://journals.openedition.org/studifrancesi/2110 ; DOI : https://doi.org/ 10.4000/studifrancesi.2110

Questo documento è stato generato automaticamente il 18 settembre 2020.

\section{(c)}

Studi Francesi è distribuita con Licenza Creative Commons Attribuzione - Non commerciale - Non opere derivate 4.0 Internazionale. 


\title{
Aa. Vv., Langue et sens du «Quart Livre», Actes du Colloque, réunis par Franco Giacone
}

\author{
Michele Mastroianni
}

\section{NOTIZIA}

AA. VV., Langue et sens du «Quart Livre», «Actes du Colloque organisé à Rome en novembre 2011», réunis par Franco GIACONE, Paris, Classiques Garnier, 2012 («Les mondes de Rabelais», 1), pp. 443.

1 Franco Giacone, non solo grande specialista rabelaisiano ma instancabile organizzatore di convegni sul padre di Gargantua, pubblica ora gli Atti del Colloque sul Quart Livre. I contributi qui riuniti sono i seguenti: Paola CIFARELLI, Le "Quart Livre» et ses traductions italiennes, pp. 13-25; Bruna CoNCONI, Londres, 1694: Pierre Le Motteux interpréte le "Quart Livre» de Rabelais, pp. 27-43; Heidi MAREK, Les traductions allemandes du "Quart Livre», pp. 45-67; Maria PROSHINA, Détournement proverbial dans le «Quart Livre», pp. 69-82; Gabriella MAccioccA, Tracce italiane nella lingua della medicina del «Quart Livre», pp. 83-93; AnnePascale POUEY-MOUNOU, "Se prendre aux mots comme un homme». Responsabilité verbale et gratuité du langage dans le "Quart Livre», 95-107; Mireille HUCHоN, L'or du temps, pp. 109-127; Marie-Luce DEMONET, les drôleries du "Quart Livre», pp. 129-150; Marie-Madeleine FRAGONARD, Banalité, plaisir et symbolique du végétal dans le "Quart Livre», pp. 151-168; Denis BJAÏ, Prières et oraisons dans le«Quart Livre», pp. 169-181; Romain MENINI, L'influence des «Moraulx de Plutarche» sur le "Quart Livre». D'après certaines annotations de l'exemplaire BnF GR Rés. g. R. 33, pp. 183-209; Mariane CLOSSON, Les «diables» du «Quart Livre», pp. 211-220; Frank LESTRINGANT, L'allégorie insulaire des Papimanes ("Quart Livre», chapitre XLVIII), pp. 221-231; Claude LA CHARITÉ, Rabelais lecteur d'Hippocrate dans le «Quart Livre», pp. 233-268; Daniel MÉNAGER, Les chapitres III et IV du «Quart Livre», pp. 269-280; François RIGOLOT, Gaster et les trois François. Quand Rabelais convoque Pétrarque et Habert à son «Temple de 
Vertu», pp. 281-293; Jean-Charles MONFERRAN, Des bruits du «Quart Livre», pp. 295-307; Olivier MILLET, Les décrétales et le droit canon dans le «Quart Livre», pp. 309-330; Richard COOPER, Rabelais imaginaire: autour du «Quart Livre» de 1548, pp. 331-362; Jacques BERCHTOLD, L'insularité, de Rabelais à Rousseau: Quel saut épistémologique?, pp. 363-379; Valerio CORDINER, «Au plus bas sens»: l'explicit panurgique du «Quart Livre», pp. 381-397; Aya IWASHITA-KAJIRO, Fabriquer des monstres. Le «Quart Livre» et l'art des grotesques, pp. 399-409; Franco GIACONE, Relecture de l'épisode de l'Isle des Papefigues («Quart Livre», XLV-XLVII), pp. 411-431.

Dopo tre comunicazioni dedicati a traduzioni di Rabelais (in italiano, in inglese e in tedesco) la prima giornata del convegno si è occupata di particolarità linguistiche del testo rabelaisiano, come lo stravolgimento del significato dei proverbi o delle formules figées praticato regolarmente, o l'uso di un linguaggio medico mutuato dall'italiano. Si è passati quindi, nelle giornate seguenti, al problema del sens, centrale per tutta l'opera di Rabelais, ma in particolare per i tre ultimi libri. Buona parte delle comunicazioni ha rintracciato nelle ascendenze culturali (alchemiche, di generi letterari medievali, iconologiche, ecc.) le chiavi interpretative di un Quart Livre fortemente simbolico. In questo servirsi dell'eredità del passato entra in gioco il meccanismo - ricorrente in Rabelais - del renversement: tipico l'esempio (studiato qui da François Rigolot) dell'evocazione parodica dell'ascesa petrarchesca al monte Ventoux, che assume un valore simbolico rovesciato. Com'è normale in un convegno che affronta un testo così complesso e polivalente, i vari contributi vertono in genere su pagine isolate del Quart Livre, per cui è difficile in questa sede renderne conto nella loro interezza. Ciononostante, si può sottolineare come partendo da passi specifici si sviluppi un discorso di grande interesse e si apporti del materiale probante per risolvere alcuni dei grandi problemi posti dai testi di Rabelais, soprattutto per quanto concerne i rapporti con il vasto dibattito intorno alle esigenze portate avanti, in varia misura, dai riformati, dagli evangelici e anche dagli erasmiani. 